\title{
Analysis of Sentinel Lymph Node Biopsy on Clear Cell Sarcoma Treatment
}

\author{
Eurico Cleto Ribeiro de Campos, Marcos Gonçalves Adriano Júnior¹, \\ Marcus Rivabem Winheski², Ricardo Poroski², Diego Sanches², Robson Menezes Leal2, \\ Marcela Cavalcanti ${ }^{3}$, Emanuela Benevides Poyer ${ }^{4}$, Renan Martins ${ }^{5}$
}

\footnotetext{
${ }^{1}$ Department of Melanoma and Soft Tissue Sarcoma from Prevent Senior São Paulo Group, São Paulo, Brasil

${ }^{2}$ Oncology Surgical Department of Evangélico Mackenzie University Hospital, Curitiba, Paraná

${ }^{3}$ Department of Pathology Neopath, Curitiba, Paraná, Brasil

${ }^{4}$ Department of Clinical Oncology from Evangélico Mackenzie University Hospital

${ }^{5}$ Ponta Grossa State University, Paraná, Brasil

Email: euricocrcampos@gmail.com, marcos.adriano@preventsenior.com.br, mrivabem@yahoo.com.br, rporoski@gmail.com, diegosanches10@gmail.com, rob-leal10@hotmail.com, marcela@neopath.com.br, copr@centrodeoncologia.com,

martinsrenanmd@gmail.com
}

How to cite this paper: de Campos, E.C.R., Adriano Júnior, M.G., Winheski, M.R., Poroski, R., Sanches, D., Leal, R.M., Cavalcanti, M., Poyer, E.B. and Martins, R. (2020) Analysis of Sentinel Lymph Node Biopsy on Clear Cell Sarcoma Treatment. Journal of Cancer Therapy, 11, 785-792. https://doi.org/10.4236/jct.2020.1112068

Received: August 11, 2020

Accepted: December 12, 2020

Published: December 15, 2020

Copyright $\odot 2020$ by author(s) and Scientific Research Publishing Inc. This work is licensed under the Creative Commons Attribution International License (CC BY 4.0).

http://creativecommons.org/licenses/by/4.0/

\begin{abstract}
Clear Cell Sarcoma (CCS) is a rare soft tissue sarcoma that corresponds to a less than $1 \%$ of all sarcomas and is a high degree neoplasm with propensity to disseminate to regional lymph nodes. Regional lymphadenectomies have a controversial impact on sarcomas treatment and survival, even though those patients have higher local recurrence and lower survival. So, sentinel lymph node biopsy must be one option for better regional staging to STS with higher propensity to lymph node commitment. The authors demonstrate two cases of CCS submitted to surgery through compartmental resection associated with the sentinel lymph node biopsy. A literature review about soft tissue sarcoma and lymph node sentinel biopsy is shown as an initial experience of two cases.
\end{abstract}

\section{Keywords}

Clear Cell Sarcomas, Soft Tissue Sarcoma, Sentinel Biopsy

\section{Introduction}

Clear Cell Sarcoma (CCS) represents less than $1 \%$ of all sarcomas, which is characterized as a rare and aggressive neoplasm [1]. Also called Melanoma of Soft Parts, it can generate, at times, some diagnostic issues when compared to primary cutaneous melanoma [1] [2] [3]. Notably, at the cytogenetic level, it exhi- 
bits the presence of a characteristic and reciprocal chromosomal translocation $\mathrm{t}(12,22)$ (q13, q12) resulting in the fusion of the EWS and $A T F 1$ genes [1] [2] [3] [4] [5].

Like all the sarcoma tumors, in a great proportion, it tends to affect the extremities. Head and neck, in addition to the trunk, are less often affected [6] [7]. Among the subtypes of soft-tissue sarcoma, CCS is highlighted as one of the tumors that remarkably reach the local lymph nodes very frequently, making it possible to obtain a number up to $40 \%$ of histologically positive lymph nodes [3]. Historically, the regional lymph nodes are compromised in some extent between $2 \%$ to $7 \%$ of sarcomas, raising the risk of involvement according to the histological subtype, like: epithelioid, rhabdomyosarcoma, synovial, angiosarcoma and the clear cell sarcoma [6]-[16].

Therefore, the sentinel lymph node (SN) appears as a locoregional staging tool for sarcomas in a more accurate manner, allowing the more radical surgical treatment, appropriate in the search for a better locoregional control taxes and at a distance [7] [13].

\section{Objective}

To present two surgically treated clear cell sarcoma cases that have gone through compartmental resection, performed in association with the sentinel lymph node technique. All the patients assign an informed consent before the mean procedure authorizing the use of clinical information and imagens by the authors.

\section{Case Reports}

Case 1. 81-year-old female patient, with a soft tissue lesion on the posterior side of the left leg, with a diagnosis of clear cell sarcoma, confirmed by histopathological findings and immunohistochemistry done through the puncture (core biopsy) guided by image examination. The patient's main complaint was a mass in the left leg topography with pain and bleeding. The patient had arterial hypertension and diabetes mellitus. Due to advanced age and comorbidities, and being a lesion susceptible to adequate surgical margins, the patient underwent surgery. A tridimensional resection was done to treat the lesion with free surgical margins, adding the strategy of sentinel lymph node on the left inguinal topography. Through the application of perilesional and intradermal Patent Blue V $(1-2 \mathrm{~mL})$ with massage in the local area of the lesion for about 5 to 10 minutes, the sentinel lymph node was identified, removed and underwent histological study. The postoperative report of the pathological examination verified the clear cell sarcoma diagnosis with free surgical margins and sentinel lymph node histologically negative. Due to the comorbidities and the advanced age, the patient did not receive any adjuvant treatment. The surgery was performed on February 2020 and until November 2020 there were no signs of locoregional recurrence or a distance. The follow up was done with physical exam and computer extremity tomography every three months (Figures 1-3). 
Case 2. 40-year-old female patient, Ecog 0 (eastern cooperative oncology group) with a tumoral mass at the medial topographic site of the right thigh, located at the adductor compartment, with a computed tomography guided biopsy and histopathological examination report of clear cell sarcoma. The patient did not have any comorbidly. The main symptom was tight pain and a limited inferior extremity adduction. A neoadjuvant treatment was realized with three cycles of doxorubicin and ifosfamide, using a dose of $60 \mathrm{mg} / \mathrm{m}^{2}$ and $5000 \mathrm{mg} / \mathrm{m}^{2}$, respectively during the period of February and march of 2020. Based on Recist criteria (response evaluation criteria in solid tumours), the patient revealed a partial response and undergone a tridimensional resection surgery in the adductor compartment and a sentinel lymph node dissection at groin topography
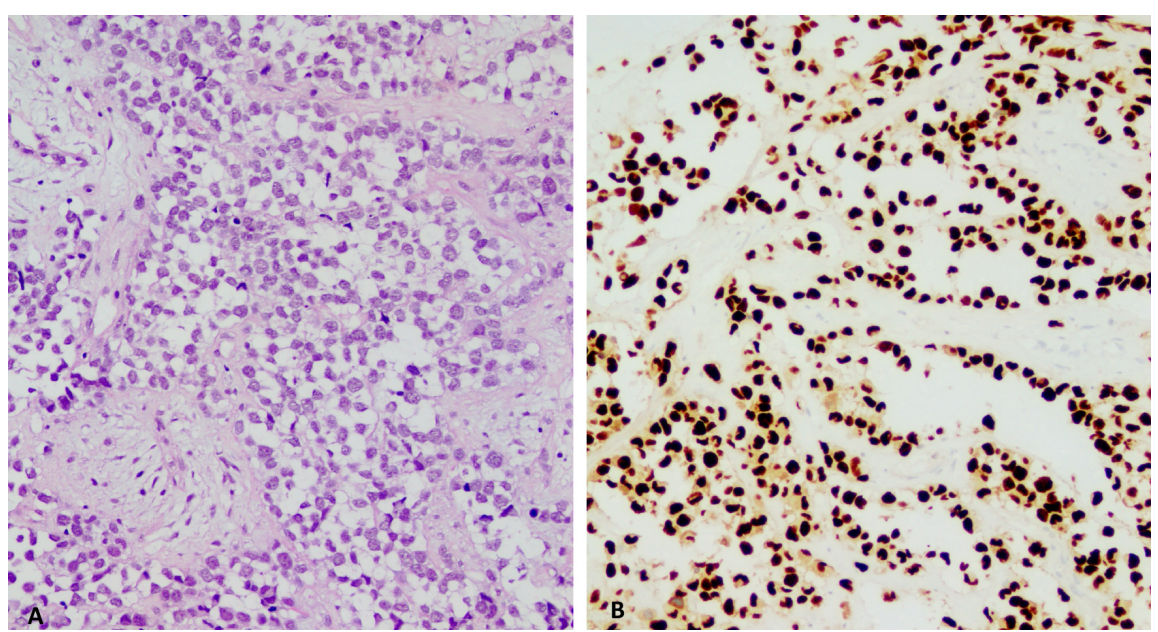

Figure 1. Histological diagnosis of the primary lesion. (A) Neoplasm composed by relativelly monomorphic cells with a clear cytoplasm. Hematoxylin and eosin stain. (B) Immunohistochemistry. S100 - 0009: S100, SOX10-200X - 0007: SOX10, HMB45 400X rare cells pos. MelanA 200X rare cells pos.

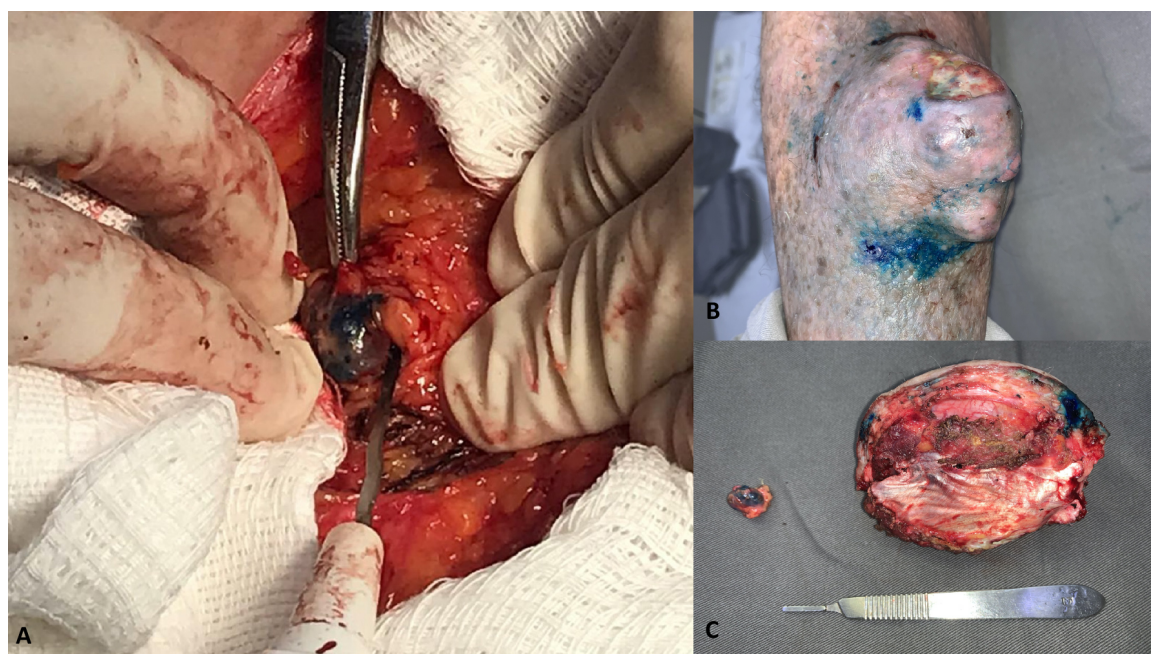

Figure 2. (A) Identification of sentinel lymph node on inguinal topography, ipsilateral to the soft-tissue lesion. (B) Clear cell sarcoma. (C) Specimen of CCS compartmental resection of the left leg. 
on $04 / 23 / 2020$. The reconstruction was done with a fasciocutaneous flap of anterior portion of the thigh founded on reverse flux circulation of the superior genicular artery and descending circumflex artery.

The postoperative pathological examination has been confirmed presenting the clear cell sarcoma diagnosis with free surgical margins and $40 \%$ of viable tumoral cells. After 6 weeks of postoperative period, the patient was referred to adjuvant radiotherapy treatment. The radiotherapy was performed from $06 / 22 / 2020$ to $08 / 03 / 2020$ with a total dose of $60 \mathrm{~Gy}$. The follow up was done with physical exam and computer extremity tomography every three months. After seven months from surgery, the patient has not any signal of locoregional or a distance (Figure 4).

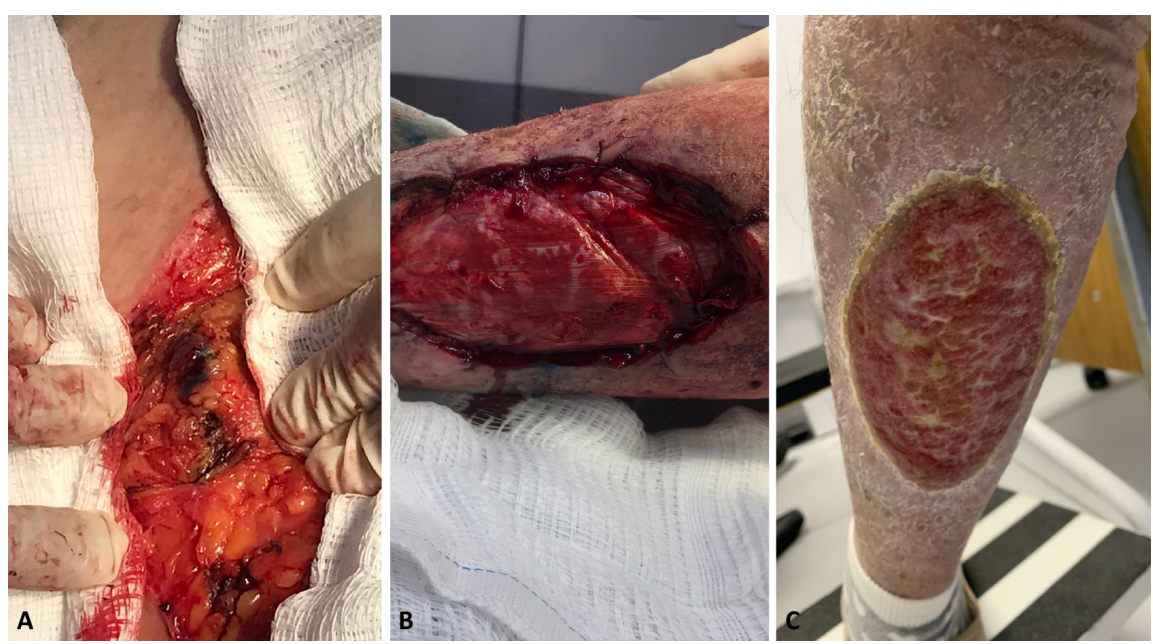

Figure 3. (A) Detection of the sentinel lymph node by the usage of Patent Blue injection. (B) Surgical aspect after the tridimensional resection of the lesion. (C) Scarring/closure aspect of the surgical wound after reconstruction with a skin graft.

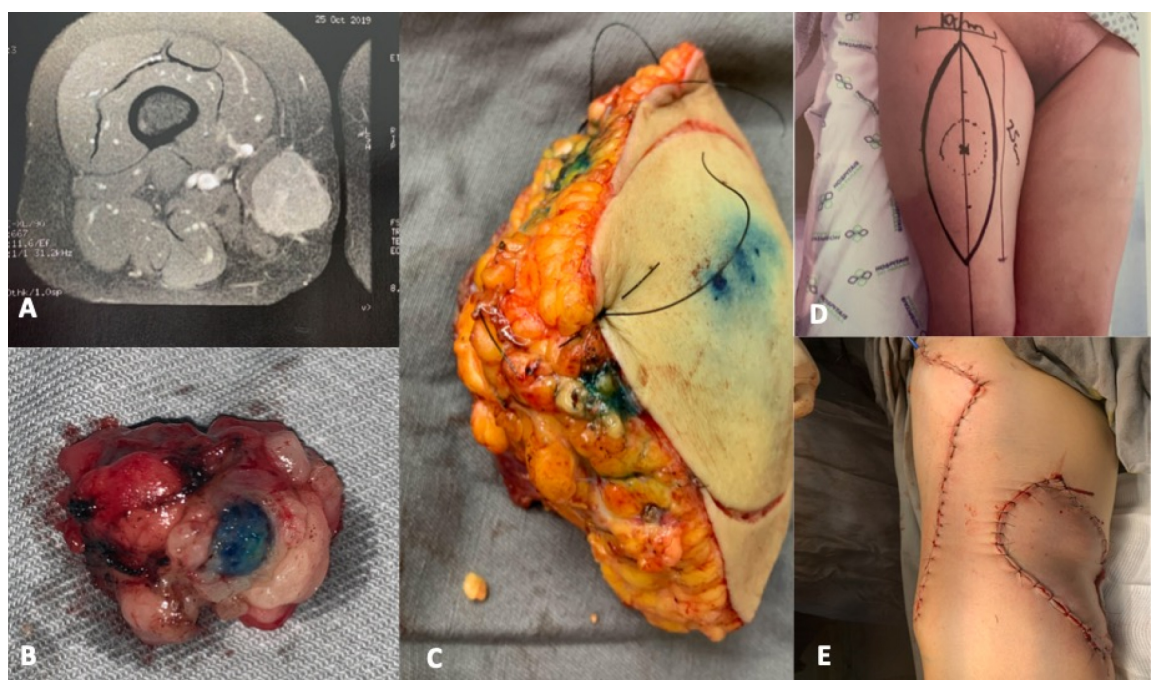

Figura 4. (A) Computed tomography of the thigh that demonstrates a soft tissue tumor in medial and adductor compartment. (B) Tridimensional resection specimen (Soft-tissue sarcoma). (C) Reconstruction technique. (D) Immediate postoperative surgical aspect. 


\section{Discussion}

The Soft-tissue sarcomas (STS) are rare tumors, affecting almost $1 \%$ of the population. In the presence of metastatic disease, the lung is the most common site affected in up to $30 \%$, as a synchronous or metachronous cancer [17].

Histologically positive lymph nodes are a determinant factor of lower survival rates in STS, as less than 28.2 months, varying by histology, in the absence of at distance metastasis [6]. The radical regional lymphadenectomy becomes relevant, in the guarantee of improvement in the prognostic prediction and survival rate. Besides that, a few patients present with positive lymph nodes, and the radical lymphadenectomies, in this context, can raise the number of morbidities as lymphedema and wound related complications in a context of low [6].

The sentinel node (SN) is the first lymph node to receive the lymphatic drainage coming from the tumor and the absence of tumoral cells at the lymph node removes the possibility of other lymph nodes involvement, theoretically [9]. This concept is based on the preconized ideas of William Halsted and demonstrated on radical mastectomy techniques, in which there is a sequential pattern of lymphatic dissemination [9].

The sentinel lymph node guarantees an accurate histological evaluation of lymph nodes and emerges as an alternative for radical regional lymphadenectomy, preventing acute complications and the chronic ones, like seroma, dehiscence, necrosis, surgical wound infection, as well as lymphedema [9] [10] [15].

The sentinel node technique was firstly described by Cabanas [18], in 1977, posteriorly evaluated by Morton on the surgical treatment of primary cutaneous melanoma, in the nineties [19]. Its application, in the treatment of STS, remains controversial.

There is a small number of studies analyzing the utilization of sentinel nodes in the treatment of Soft-tissue sarcomas. In a metanalysis with 144 treated patients, the commitment rate of sentinel lymph node was $12 \%$, with false negative rates up to $29 \%$. Patients having positive SL presented with lower survival rates compared to the patients with negative sentinel lymph nodes [9].

Van Akkoi et al. [7] analyzed the role of sentinel biopsy on CCS surgical treatment. Those patients who presented positive sentinel biopsy were the patients that showed other positive lymph nodes beyond the sentinel node. The SN positivity predicts local recurrence and lower survival.

Andreou et al. [10] analyzed the implication of SN in the treatment of the STS subtypes that more frequently compromise the lymph nodes, like synovial sarcoma, epithelioid, clear cell sarcoma, and rhabdomyosarcoma in a total of 62 patients. Twelve patients were clear cell sarcoma carriers, and in six of them, the SN was histologically positive. No false negative cases were reported. Taking the group of the six clear cell sarcoma patients, two of them presented to the medical team with positive lymph nodes beyond the SN. The patients with positive lymph nodes beyond the sentinel lymph node, evolved with distant recurrence and death, showing higher disease volume. In this way, the finding of a positive 
sentinel lymph node is an important marker of worse evolution of the disease in Clear Cell Sarcoma [10].

In 14 Chinese patients with clear cell sarcoma, two of them underwent the SN technique. None of them presented positive lymph node or locoregional recurrence during the follow-up, but all of the patients evolved to death by distant recurrence. The criteria that have been used for the $\mathrm{SN}$ search were to englobe patients at Clinical Stage II STS [20].

Nishida et al. [12] identified, through the Patent Blue V technique, six sentinel lymph nodes in a patient diagnosed with clear cell sarcoma of extremities. The author made a complementary radical regional lymphadenectomy, showing no evidence of histologically positive beyond the SL tested. In the author's view, the search for the SL in clear cell sarcoma is feasible, with low morbidity and, in this case, without false negatives [12].

In our study, the sentinel lymph node was identified in both two patients, by the Blue Patent technique, with negative histological results. In spite of a short follow-up period, the patients don't show locoregional recurrence or a distance, there being no false negative cases until the moment.

Considering the two cases of CCS presented, the lymph node sentinel biopsy is a feasible technique that better accurate the lymph none status without the major complications of a regional lymphadenectomy. The lymph node sentinel biopsy can be done at the same moment of the surgeon remove a skin graft at the groin to recover the surgical site or when a pediculated fasciocutaneous flap has been prepared, avoiding any additional complication due to a specific dissection for a better lymph node staging.

\section{Conclusions}

Soft-tissue sarcomas are a heterogeneous group of neoplasms. The main differences are the anatomic site committed, the patterns of dissemination (lymphatic or venous or both) and the molecular profiles. These differences between the STS subtypes can justify the different rates of lymph node commitment that were found on literature, as the different values of false negative detected with the lymph node sentinel technique. Technical issues also can contribute to different results.

New studies are necessary to better demonstrate the real impact of sentinel technique on STS treatment, especially in CCS, since the extrapolation of the results from cutaneous melanoma and breast carcinoma with the sentinel lymph node technique, do not permit to accurately define the true impact of this technique in the surgical treatment of clear cell soft-tissue sarcomas.

\section{Conflicts of Interest}

The authors declare no conflicts of interest regarding the publication of this paper. 


\section{References}

[1] Juel, J. and Ibrahim, R.M. (2017) A Case of Clear Cell Sarcoma-A Rare Malignancy. International Journal of Surgery Case Reports, 36, 151-154. https://doi.org/10.1016/j.ijscr.2017.05.034

[2] Falconieri, G., Bacchi, C.E. and Luzar, B. (2012) Cutaneous Clear Cell Sarcoma: Report of Three Cases of a Potentially Underestimated Mimicker of Spindle Cell Melanoma. The American Journal of Dermatopathology, 34, 619-625. https://doi.org/10.1097/DAD.0b013e3182473190

[3] Fantini, F., Monari, P., Bassissi, S., Maiorana, A. and Cesinaro, A.M. (2007) Sentinel Lymph Node Biopsy in Clear Cell Sarcoma. Journal of the European Academy of Dermatology and Venereology, 21, 1271-1272. https://doi.org/10.1111/j.1468-3083.2007.02164.x

[4] Dim, D.C., Cooley, L.D. and Miranda, R.N. (2007) Clear Cell Sarcoma of Tendons and Aponeuroses: A Review. Archives of Pathology \& Laboratory Medicine, 131, 152-156.

[5] Albores-Zúñiga, O., Padilla-Rosciano, A.E., Martínez-Said, H., Cuéllar-Hubbe, M. and Ramírez-Bollas, J. (2006) Clear Cell Sarcoma and Sentinel Lymph Node Biopsy. Case Report and Literature Review. Cirugia y Cirujanos, 74, 121-125.

[6] Keung, E.Z., Chiang, Y.J., Voss, R.K., Cormier, J.N., Torres, K.E., Hunt, K.K., Feig, B.W. and Roland, C.L. (2018) Defining the Incidence and Clinical Significance of Lymph Node Metastasis in Soft Tissue Sarcoma. European Journal of Surgical Oncology, 44, 170-177. https://doi.org/10.1016/j.ejso.2017.11.014

[7] van Akkooi, A.C., Verhoef, C., van Geel, A.N., Kliffen, M., Eggermont, A.M. and de Wilt, J.H. (2006) Sentinel Node Biopsy for Clear Cell Sarcoma. European Journal of Surgical Oncology, 32, 996-999. https://doi.org/10.1016/j.ejso.2006.03.044

[8] Andreou, D., Boldt, H., Werner, M., Hamann, C., Pink, D. and Tunn, P.U. (2013) Sentinel Node Biopsy in Soft Tissue Sarcoma Subtypes with a High Propensity for Regional Lymphatic Spread-Results of a Large Prospective Trial. Annals of Oncology, 24, 1400-1405. https://doi.org/10.1093/annonc/mds650

[9] Wright, S., Armeson, K., Hill, E.G., Streck, C., Leddy, L., Cole, D., Esnaola, N. and Camp, E.R. (2012) The Role of Sentinel Lymph Node Biopsy in Select Sarcoma Patients: A Meta-Analysis. The American Journal of Surgery, 204, 428-433.

https://doi.org/10.1016/j.amjsurg.2011.12.019

[10] Andreou, D. and Tunn, P.U. (2009) Sentinel Node Biopsy in Soft Tissue Sarcoma. Recent Results in Cancer Research, 179, 25-36. https://doi.org/10.1007/978-3-540-77960-5 3

[11] Maduekwe, U.N., Hornicek, F.J., Springfield, D.S., Raskin, K.A., Harmon, D.C., Choy, E., Rosenberg, A.E., Nielsen, G.P., DeLaney, T.F., Chen, Y.L., Ott, M.J. and Yoon, S.S. (2009) Role of Sentinel Lymph Node Biopsy in the Staging of Synovial, Epithelioid, and Clear Cell Sarcomas. Annals of Surgical Oncology, 16, 1356-1363. https://doi.org/10.1245/s10434-009-0393-9

[12] Nishida, Y., Yamada, Y., Tsukushi, S., Shibata, S. and Ishiguro, N. (2005) Sentinel Lymph Node Biopsy Reveals a Positive Popliteal Node in Clear Cell Sarcoma. Anticancer Research, 25, 4413-4416.

[13] Picciotto, F., Zaccagna, A., Derosa, G., Pisacane, A., Puiatti, P., Colombo, E., Dardano, F. and Ottinetti, A. (2005) Clear Cell Sarcoma (Malignant Melanoma of Soft Parts) and Sentinel Lymph Node Biopsy. European Journal of Dermatology, 15, 46-48. 
[14] Al-Refaie, W.B., Ali, M.W., Chu, D.Z., Paz, I.B. and Blair, S.L. (2004) Clear Cell Sarcoma in the Era of Sentinel Lymph Node Mapping. Journal of Surgical Oncology, 87, 126-129. https://doi.org/10.1002/jso.20096

[15] Blazer, D.G. 3rd, Sabel, M.S. and Sondak, V.K. (2003) Is There a Role for Sentinel Lymph Node Biopsy in the Management of Sarcoma? Surgical Oncology, 12, 201-206. https://doi.org/10.1016/S0960-7404(03)00030-6

[16] Fong, Y., Coit, D.G., Woodruff, J.M. and Brennan, M.F. (1993) Lymph Node Metastasis from Soft Tissue Sarcoma in Adults. Analysis of Data from a Prospective Database of 1772 Sarcoma Patients. Annals of Surgery, 217, 72-77. https://doi.org/10.1097/00000658-199301000-00012

[17] Duran-Moreno, J., Kontogeorgakos, V. and Kouumarianou, A. (2019) Soft Tissue Sarcomas of the Upper Extremities: Maximizing Treatment Opportunities and Outcomes. Oncology Letters, 18, 2179-2191. https://doi.org/10.3892/ol.2019.10575

[18] Cabanas, R.M. (1977) An Approach for the Treatment of Penile Carcinoma. Cancer, 39, 456-466. https://doi.org/10.1002/1097-0142(197702)39:2<456::AID-CNCR2820390214>3.0.C $\underline{\mathrm{O} ; 2-\mathrm{I}}$

[19] Amersi, F. and Morton, D.L. (2007) The Role of Sentinel Lymph Node Biopsy in the Management of Melanoma. Advances in Surgery, 41, 241-256. https://doi.org/10.1016/j.yasu.2007.05.015

[20] Lee, H.L., Ho, W.Y., Lam, Y.L., et al. (2014) Prognostic Factors Associated with Clear Cell Sarcoma in 14 Chinese Patients. Journal of Orthopaedic Surgery, 22, 236-239. https://doi.org/10.1177/230949901402200226 